\title{
Electrodeposited Ni-W-TiC Composite Coatings: Effect of TiC Reinforcement on Microstructural and Tribological Properties
}

\author{
Jin Hyuk Choi ${ }^{1} \cdot$ Gobinda Gyawali $^{2} \cdot$ Dhani Ram Dhakal $^{3} \cdot$ Bhupendra Joshi $^{2} \cdot$ Soo Wohn Lee $^{3}$
}

Received: 19 September 2019 / Revised: 1 November 2019 / Published online: 5 February 2020

(c) The Chinese Society for Metals (CSM) and Springer-Verlag GmbH Germany, part of Springer Nature 2020

\begin{abstract}
$\mathrm{Ni}-\mathrm{W}-\mathrm{TiC}$ composite coatings were prepared via electrodeposition technique by dispersing the different amount of TiC particles into the plating bath. The Ni-W and Ni-W-TiC composite coatings containing different concentrations of TiC particles were characterized by using the scanning electron microscope, $\mathrm{X}$-ray diffraction technique, Vickers microhardness test, surface roughness test, and tribology test. The results show that the $\mathrm{Ni}-\mathrm{W}$ coatings containing reinforced TiC particles have shown a typical FCC Ni-W crystal structure with significantly higher Vickers microhardness. The amount of dispersed $\mathrm{TiC}$ particles into the plating bath considerably affected codeposition weight percent of $\mathrm{TiC}$ into the $\mathrm{Ni}-\mathrm{W}$ matrix, as revealed by the EDS analysis. Ni-W-TiC samples demonstrated the decreased abrasive wear as compared to Ni-W coating and no characteristic features observed for the adhesive wear. Similarly, an improvement in coefficient of friction was observed in $\mathrm{Ni}-\mathrm{W}-\mathrm{TiC}$ composite coating as compared to $\mathrm{Ni}-\mathrm{W}$ coating.
\end{abstract}

Keywords Ni-W alloy $\cdot$ Composite coating $\cdot$ Microhardness $\cdot$ Wear $\cdot$ Coefficient of friction

\section{Introduction}

Electrodeposited nickel and $\mathrm{Ni}$ alloys are potential engineering materials for various applications due to their excellent characteristics such as higher microhardness, toughness, wear and corrosion resistance [1,2], strength at high and low temperatures, and a range of special magnetic, thermal and electronic properties [3]. The application of nickel extends from our essential utilities such as food processing equipment to the advanced multifunctional gadgets, including smartphones and computers. Similarly, lustrous decorative topcoat, medical equipment, cutting tools, transportation,

Available online at http://link.springer.com/journal/40195

Gobinda Gyawali

ggobinda@sunmoon.ac.kr

1 Department of Materials Metal Engineering, Sun Moon University, 31460 Asan, South Korea

2 Department of Fusion Science and Technology, Sun Moon University, Tangjeong Myeon, 31460 Asan, Chungnam, South Korea

3 Department of Environmental and Bio-Chemical Engineering, Sun Moon University, 31460 Asan, South Korea buildings, power generation, etc., also utilize $\mathrm{Ni}$ or Ni-alloy coatings. Electrodeposition of tungsten (W) is very difficult, but the studies have revealed that $\mathrm{W}$ can be alloyed along with other transition metals such as $\mathrm{Ni}$ [4] or Co [5] by the electrodeposition process. Alloying $\mathrm{W}$ with $\mathrm{Ni}$ appears to be more practical in terms of industrial point of view because $\mathrm{Ni}-\mathrm{W}$ alloy holds enhanced mechanical properties than the nickel-only coating. It is due to the formation of the FCC $\mathrm{Ni}-\mathrm{W}$ alloy phase with reduced grains that possess an excellent hardening effect [6].

Metal matrix composite coatings offer several unusual combinations of properties that are difficult to achieve from either a single metal/alloy coating or only the sintered ceramics [7]. Several techniques are available to produce metal matrix composite coatings such as casting techniques and powder metallurgy methods [8], accumulative roll bonding (ARB), plasma spraying, electrophoretic deposition (EPD), electrolytic deposition, electroless deposition, hot-press sintering, ice templating, and pressure infiltration $[9,10]$. Among the various techniques, electrodeposition is yet a low-cost, efficient, and effective technique to produce metal matrix composites. Reinforcement of ceramic particles into the nickel or nickel alloy coatings during the electrodeposition process, so-called composite electrodeposition, further improves the microstructural, 
mechanical, tribological [4], and corrosion-resistant properties [11]. Metal matrix composite coatings are applied in various sectors, including mechanical, thermal, electronic, electrical, and engineering, where there is an immediate need for wear and corrosion protection. For the tribological applications, metal matrix composites should support a load without distortion, deformation, or fracture during high-temperature operation and to maintain steady-state friction and wear [12]. Hou et al. [13] studied the tribological properties of the $\mathrm{Ni}-\mathrm{W}-\mathrm{Al}_{2} \mathrm{O}_{3}$ composites and reported that the incorporation of hard $\mathrm{Al}_{2} \mathrm{O}_{3}$ particles into the $\mathrm{Ni}-\mathrm{W}$ matrix decreased the wear and coefficient of friction. Similarly, excellent wear and corrosion-resistant properties of the $\mathrm{Ni}-\mathrm{W}$ coatings containing $\mathrm{SiC}$ as the reinforced phase were reported by Li et al. [14]. Besides, the distribution of ceramic particles in the metal/alloy matrix, ceramic particles shape and size, hardness, and their volume fraction also play a vital role in the tribological application.

On the other hand, TiC possesses high hardness, high melting temperature, and excellent thermal and chemical stabilities. Therefore, $\mathrm{TiC}$ is used as the hardening phase of superalloys or the reinforcement in metal matrix composites to manufacture high-stress wear-resistant tools, cutting tools, coating for abrasive steel bearings, etc.[15, 16]. Although $\mathrm{TiC}$ possesses exceptional mechanical properties, studies on utilization of $\mathrm{TiC}$ as reinforcement in the electrodeposited $\mathrm{Ni}-\mathrm{W}$ system and their influence on tribological behavior have not been carried out yet with our best knowledge. Hence, the present study aims to investigate the influence of $\mathrm{TiC}$ particles codeposition on the morphological, microstructural, mechanical, and tribological properties of the Ni-W-TiC composites.

\section{Experimental}

\subsection{Chemicals}

Nickel sulfate $\left(\mathrm{NiSO}_{4} \cdot 6 \mathrm{H}_{2} \mathrm{O}, 99 \%\right.$ purity, Sigma-Aldrich) and sodium tungstate $\left(\mathrm{Na}_{2} \mathrm{WO}_{4} \cdot 2 \mathrm{H}_{2} \mathrm{O}, 99 \%\right.$ purity, Sigma-Aldrich) were used as the sources of $\mathrm{Ni}$ and $\mathrm{W}$, respectively. Sodium bromide $(\mathrm{NaBr}, 99 \%$ purity, SigmaAldrich) was used to maintain electrolytic bath conductivity. Similarly, trisodium citrate $\left(\mathrm{Na}_{3} \mathrm{C}_{6} \mathrm{H}_{5} \mathrm{O}_{7} \cdot \mathrm{H}_{2} \mathrm{O}, 98 \%\right.$ purity, DUKSAN pure chemicals) and ammonium chloride $\left(\mathrm{NH}_{4} \mathrm{Cl}, 98.5 \%\right.$ purity, DUKSAN pure chemicals) were used as complexing and buffering agents, respectively. Titanium carbide (TiC, Grade R, H. C. Starck GmbH) was used as the composite reinforcement phase. The chemicals were used without further purification.

\subsection{Fabrication of Ni-W-TiC Composite Coatings}

Plating bath formulation, concentration, and plating conditions are presented in Table 1. Prior to the composite electrodeposition, a requisite amount of $\mathrm{TiC}$ powder was put into the small fraction of the plating solution and dispersed for 30 min using both mechanical and ultrasound stirrings. Electrodeposition was carried out on the 2-mm-thick polished copper sheet with an exposed surface area of $2.56 \mathrm{~cm}^{2}$ which was put into the plating bath containing $0,5,10,15$, and $20 \mathrm{~g} / \mathrm{L}$ of TiC particles. Pulse current with $80 \mathrm{~mA} / \mathrm{cm}^{2}$ peak-to-peak current density, $100 \mathrm{~Hz}$ pulse frequency, and $50 \%$ pulse duty cycle were adjusted. The composite electrodeposition was set for $90 \mathrm{~min}$ for each sample. After the process, the samples were thoroughly cleaned by distilled water, followed by ultrasonic cleaning for $5 \mathrm{~min}$ to remove loosely adsorbed $\mathrm{TiC}$ particles. The samples prepared by dispersing $0,5,10,15$, and $20 \mathrm{~g} / \mathrm{L}$ of $\mathrm{TiC}$ particles in the plating bath were abbreviated as Ni-W, Ni-W-TiC5, Ni-W-TiC10, $\mathrm{Ni}-\mathrm{W}-\mathrm{TiC} 15$, and $\mathrm{Ni}-\mathrm{W}-\mathrm{TiC} 20$, respectively.

\subsection{Characterizations}

Surface morphologies of the Ni-W-TiC composite coatings were observed by scanning electron microscope (MiniSEM, Nanoeye). Microstructures and phase compositions were analyzed by X-ray diffraction (XRD, Rigaku DMAX 2200, Japan). Vickers microhardness test was carried out by applying $0.98 \mathrm{~N}$ load for $10 \mathrm{~s}$ at ten different places on the surface of the sample by using Vickers microhardness tester (Buehler Ltd., USA), and the values were averaged. Surface roughness $(R \mathrm{a}, R \mathrm{q})$ of the samples was measured by Surface Profilometer (Mitutoyo SurfTest, Japan). The weight percent of $\mathrm{W}$ and codeposited TiC particles in Ni-W-TiC composites were evaluated by using energy-dispersive $\mathrm{X}$-ray spectroscopy (EDS) analysis coupled with the SEM.

Table 1 Experimental bath formulation, concentration, and plating condition

\begin{tabular}{lll}
\hline Composition & Concentration & Purpose \\
\hline $\mathrm{NiSO}_{4} \cdot 6 \mathrm{H}_{2} \mathrm{O}$ (molar) & 0.075 & Ni source \\
$\mathrm{Na}_{2} \mathrm{WO}_{4} \cdot 2 \mathrm{H}_{2} \mathrm{O}$ (molar) & 0.112 & W source \\
$\mathrm{Na}_{3} \mathrm{C}_{6} \mathrm{H}_{5} \mathrm{O}_{7} \cdot \mathrm{H}_{2} \mathrm{O}$ (molar) & 0.187 & Complexing agent \\
$\mathrm{NH}_{4} \mathrm{Cl}($ molar) & 0.5 & Buffer \\
$\mathrm{NaBr}($ molar $)$ & 0.6 & Conductivity \\
$\mathrm{SDS}(\mathrm{g} / \mathrm{L})$ & 0.3 & Surfactant \\
$\mathrm{TiC}$ particles $(\mathrm{g} / \mathrm{L})$ & $0,5,10,20$ & Composite phase \\
Temp. $\left({ }^{\circ} \mathrm{C}\right)$ & 65 & Plating condition \\
Plating time $(\mathrm{min})$ & 90 & Plating condition \\
\hline
\end{tabular}




\subsection{Tribology Test}

Ball-on-disk tribometer (CSM Instruments; TRN 01-04879) was used to evaluate the wear and coefficient of friction (COF) of the Ni-W-TiC samples. Steel ball (SAE52100) of a measured average hardness $830 \mathrm{HV}$ and a diameter of $12.7 \mathrm{~mm}$ was used as the counterpart. Wear test was carried out in a dry condition (at $25{ }^{\circ} \mathrm{C}, 35 \%$ humidity, and no lubricant) under $5 \mathrm{~N}$ load with a sliding speed of $5 \mathrm{~cm} / \mathrm{s}$ for $10 \mathrm{~min}$. The best sample was further analyzed for wear and coefficient of friction tests by varying loads and sliding speeds. Different loads (i.e., 3 N, 5 N, 7.5 N, and 10 N) were adjusted to study the effect of applied load on the tribological performance of the Ni-W-TiC coating. The worn-out surfaces were observed and analyzed by using SEM and EDS. The coefficient of friction was recorded simultaneously during the wear test.

\section{Results and Discussion}

\subsection{Morphological and Microstructural Evaluation of the Composite Coatings}

Figure 1 shows the surface morphologies of Ni-W (Fig. 1a), $\mathrm{Ni}-\mathrm{W}-\mathrm{TiC}$ composite coatings prepared from different concentrations of TiC particles in the plating bath (Fig. 1b-e), and the TiC powder utilized in this study (Fig. 1f). The morphological differences between $\mathrm{Ni}-\mathrm{W}$ alloy coating and the Ni-W-TiC composite coatings have been clearly observed. Ni-W alloy shows a relatively compact deposit; however, few microcracks are also observed along the canals and around the larger nodules. In addition, the appearance of miniature granules throughout the surface indicates the nucleated crystals, but terminating with a short-range crystal growth suggests the alloy phase having small grain size. On the other hand, Ni-W-TiC composite coatings show homogeneous surface texture and a smaller size of nodules. As the amount of $\mathrm{TiC}$ particles increased in the plating bath, the surface gradually changed to a coarser texture. Unlike $\mathrm{Ni}-\mathrm{W}$ alloy coating, Ni-W-TiC composite coatings show less surface compactness but possessed a low-aspect-ratio granules. The reason behind the coarser texture or microclustering of grains in the Ni-W-TiC composite coatings might be due to the conductive nature of $\mathrm{TiC}$, which facilitated increased electric field around the clusters during the electrodeposition process [17]. Codeposition of ceramic particles into the metallic matrix is primarily by mechanical inclusion into the growing metal matrix, assisted by surfactants, positively charged ionic species, and the whirlpool of the plating solution. Embedment of second-phase particles hinders the unidirectional regular grain growth allowing to activate nucleation from alternative sites. Despite the phenomenon, hydrogen evolution during the electrodeposition also causes the formation of pits or small pockets containing trapped hydrogen, which is undesire for industrial coatings. The morphology suggests that Ni-W-TiC composite coatings appear to be less affected by hydrogen embrittlement but largely stimulated by the codeposited $\mathrm{TiC}$ particles. Surface roughness analysis, as shown in Fig. 2, obviously revealed
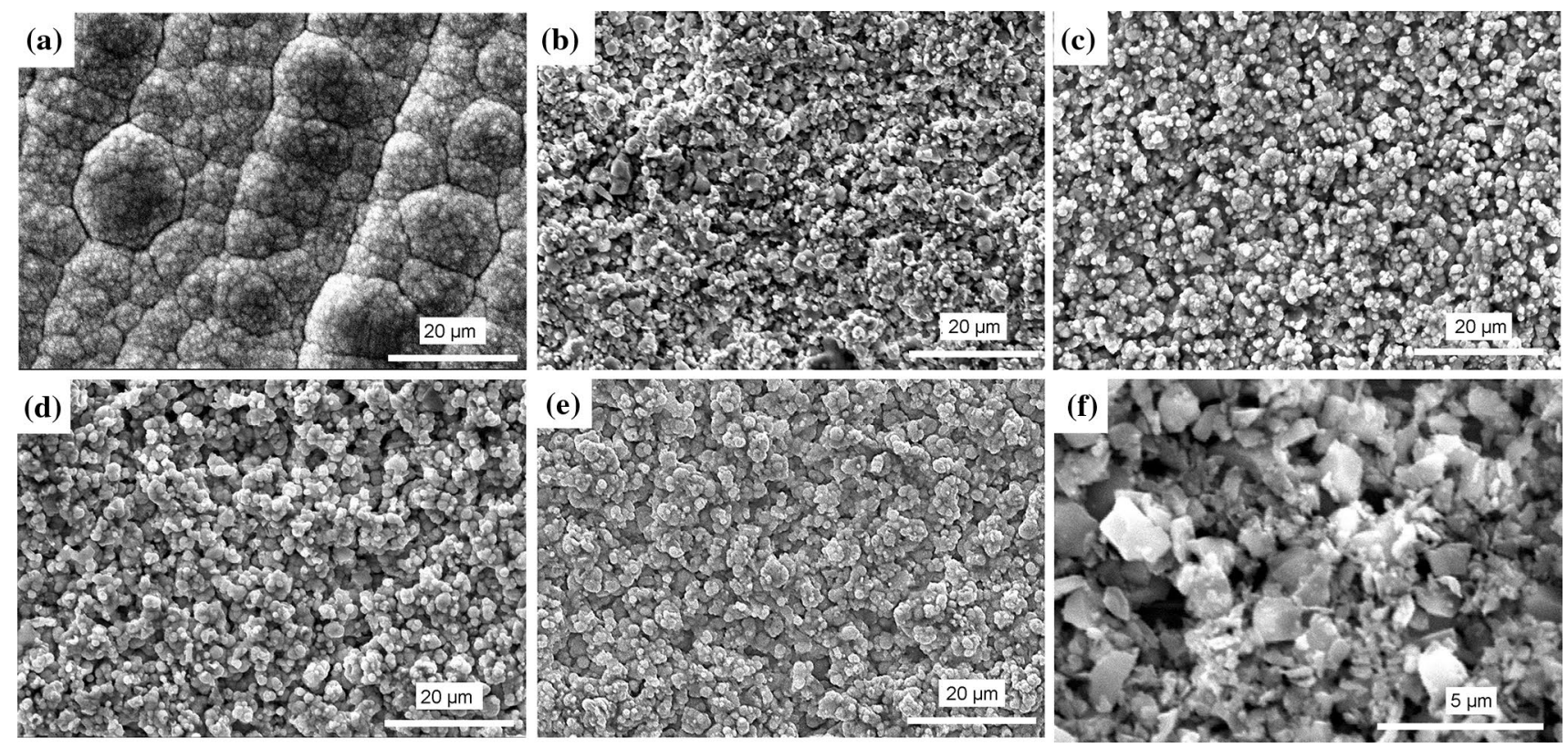

Fig. 1 SEM images of the surface morphologies of a Ni-W, b Ni-W-TiC5, $\mathbf{c}$ Ni-W-TiC10, $\mathbf{d}$ Ni-W-TiC15, e Ni-W-TiC20 coatings, and $\mathbf{f}$ TiC powder 


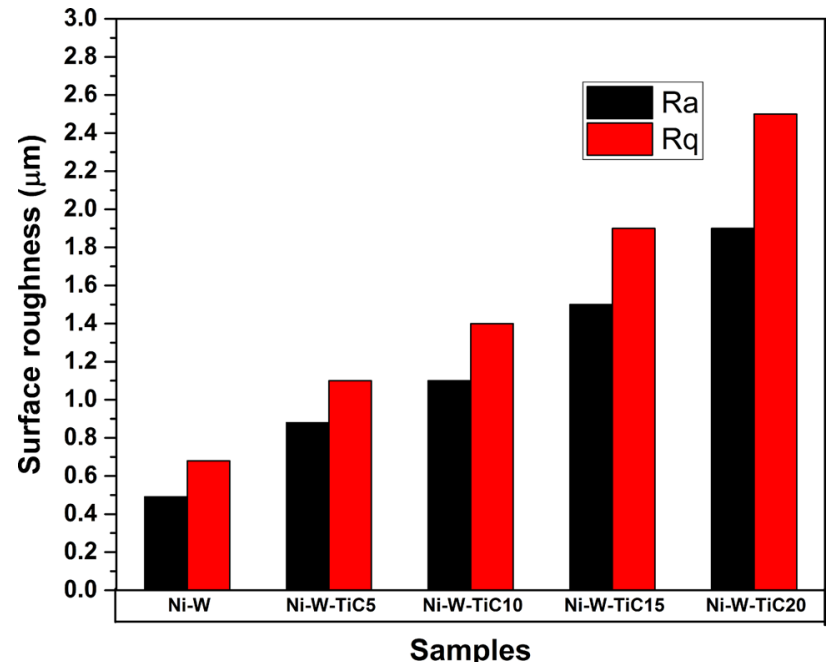

Fig. 2 Variation of surface roughness of Ni-W and Ni-W-TiC composite coatings

a significant difference between the $\mathrm{Ni}-\mathrm{W}$ and $\mathrm{Ni}-\mathrm{W}-\mathrm{TiC}$ composite coatings. The average surface roughness of $\mathrm{Ni}-\mathrm{W}$ alloy has the lowest value, and the roughness values of Ni-W-TiC coatings gradually increased by increasing the concentration of TiC particles. Since the TiC particles used in this study are submicron in size (Fig. 1f), the increased codeposition weight percent into the metal matrix presumably affected the roughness of the deposit.
A representative EDS element mapping of $\mathrm{Ni}, \mathrm{W}, \mathrm{Ti}$, and $\mathrm{C}$ in the Ni-W-TiC20 composite coating is shown in Fig. 3. The distribution of TiC particles on the surface of the deposit is not uniform but possesses a minor of agglomeration. In general, the homogeneous distribution of ceramic particles is difficult to achieve by the composite electrodeposition process because of the nature of particles, as they always tend to agglomerate in suspension. However, significant efforts such as the use of surfactants [18], ultrasonics [19], maintaining the solution flow/agitation [20], and adjusting the configuration of electrodes [21] have been made to reduce the agglomeration of the particles during electroless or electrodeposition. The homogeneous distribution of particles plays a vital role in enhancing the mechanical, tribological, and electrochemical corrosion behaviors of the coating.

$\mathrm{X}$-ray diffraction patterns of the $\mathrm{Ni}-\mathrm{W}$ alloy and Ni-W-TiC composite coatings are shown in Fig. 4a. The diffraction peaks of $\mathrm{Ni}-\mathrm{W}$ alloy suggest the crystalline FCC crystal structure without any amorphous or precipitated $\mathrm{NiWO}_{4}$ phases. The incorporation of TiC particles into the $\mathrm{Ni}-\mathrm{W}$ alloy matrix is also confirmed by the appearance of TiC peaks in the XRD spectra of the composites. The peak positions are consistent with the corresponding XRD peaks of TiC powder used in this study (Fig. 4b). Despite the TiC reinforcement, the FCC Ni-W alloy phase is preserved in the $\mathrm{Ni}-\mathrm{W}-\mathrm{TiC}$ composite coatings. Hence, from the XRD patterns, it is concluded that the $\mathrm{Ni}-\mathrm{W}-\mathrm{TiC}$ composite coatings possess a crystalline matrix phase without any associated
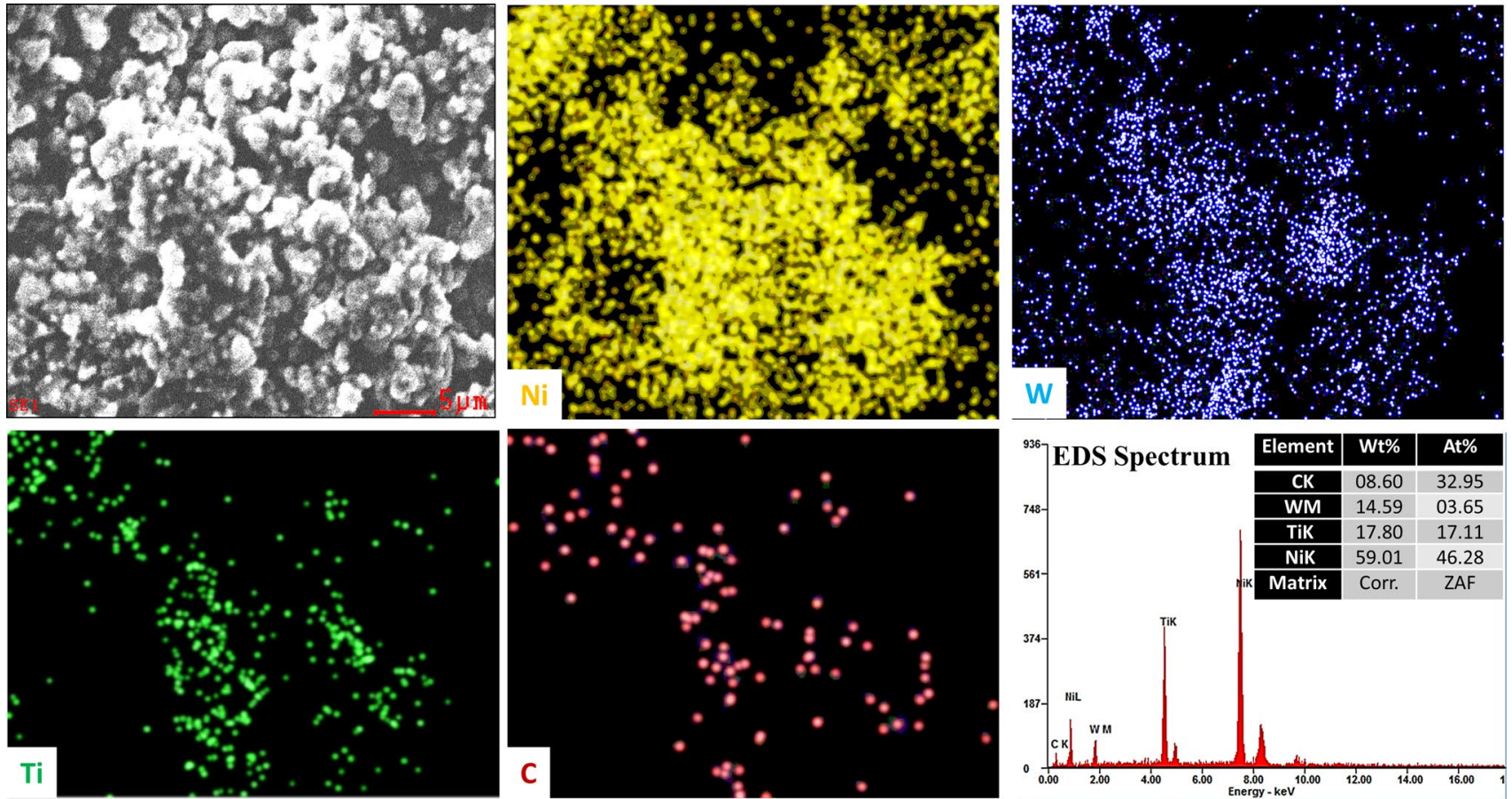

Fig. 3 EDS element mapping and spectrum of Ni-W-TiC20 sample 

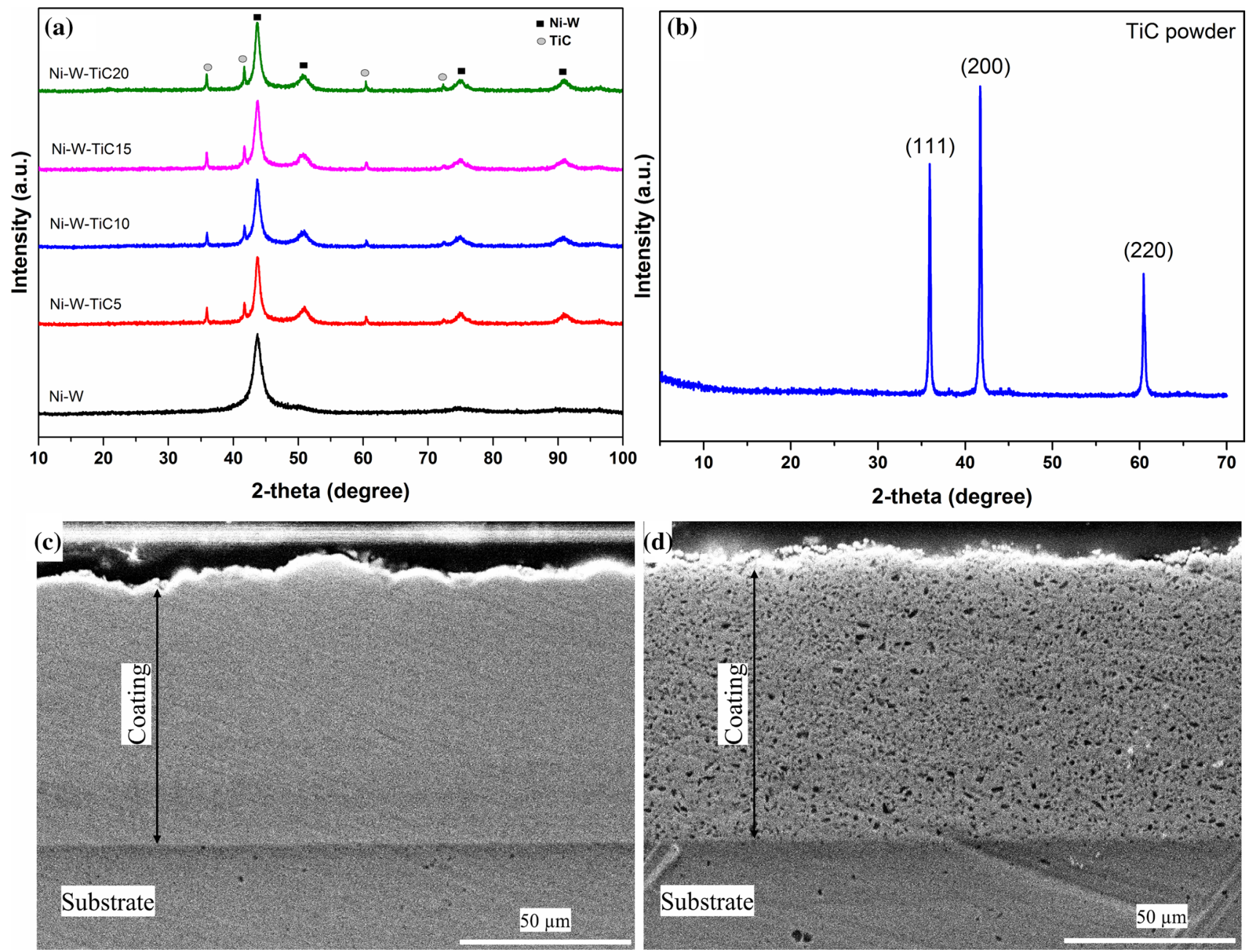

Fig. 4 X-ray diffraction patterns of a Ni-W-TiC coatings, $\mathbf{b}$ TiC powder; SEM cross-sectional images of $\mathbf{c}$ Ni-W, $\mathbf{d}$ Ni-W-TiC20 coatings

impurities or undesired phases. To determine the coating thickness, and distribution patterns of the TiC particles in the Ni-W coating, SEM cross-sectional observation of the coatings was carried out. The cross-sectional images of $\mathrm{Ni}-\mathrm{W}$ and the representative $\mathrm{Ni}-\mathrm{W}-\mathrm{TiC} 20$ composite coatings are shown in Fig. 4c, d, respectively. Both the coatings possessed an almost similar average coating thickness of $\sim 75 \mu \mathrm{m}$. The substrate-coating interface structure reveals an excellent attachment. On the other hand, TiC particles are found to be distributed throughout the Ni-W matrix.

\subsection{Microhardness}

Vickers microhardness values of $\mathrm{Ni}-\mathrm{W}$ and $\mathrm{Ni}-\mathrm{W}-\mathrm{TiC}$ composite coatings are shown in Fig. 5a. Vickers microhardness of Ni-W alloy coating is approx. $700 \mathrm{HV}$, whereas the microhardness of Ni-W-TiC composite coatings increased to nearly $1000 \mathrm{HV}$. From the plot, the microhardness of the composite coating is increased with increasing concentration of the $\mathrm{TiC}$ particles. However, by increasing the concentration of TiC from 15 to $20 \mathrm{~g} / \mathrm{L}$ in the plating bath, a significant increase in the microhardness was not measured. Therefore, the maximum concentration of $\mathrm{TiC}$ dispersion in the plating bath was maintained to $20 \mathrm{~g} / \mathrm{L}$ in this study. Since the TiC particles employed in this study are sub microns in size, the improved microhardness of the composite coating is, thus, primarily associated with the dispersion strengthening effect. On the other hand, studies have shown that the ceramics reinforcement of the metal matrix causes to decrease the grain size of the matrix and enhances the microhardness of the composite coatings [3, 22]. In our Ni-W alloy and the $\mathrm{Ni}-\mathrm{W}-\mathrm{TiC}$ composite coatings, the grain size, calculated by Scherrer's equation with reference to the broadening of (200) reflection peak in XRD, ranges in between 5 and $7 \mathrm{~nm}$ (Fig. 5b). Hence, there is not much difference in the matrix grain size of $\mathrm{Ni}-\mathrm{W}$ and $\mathrm{Ni}-\mathrm{W}-\mathrm{TiC}$ coatings. Therefore, an increase in Vickers microhardness of $\mathrm{Ni}-\mathrm{W}-\mathrm{TiC}$ composite coating is primarily associated with the dispersion hardening 

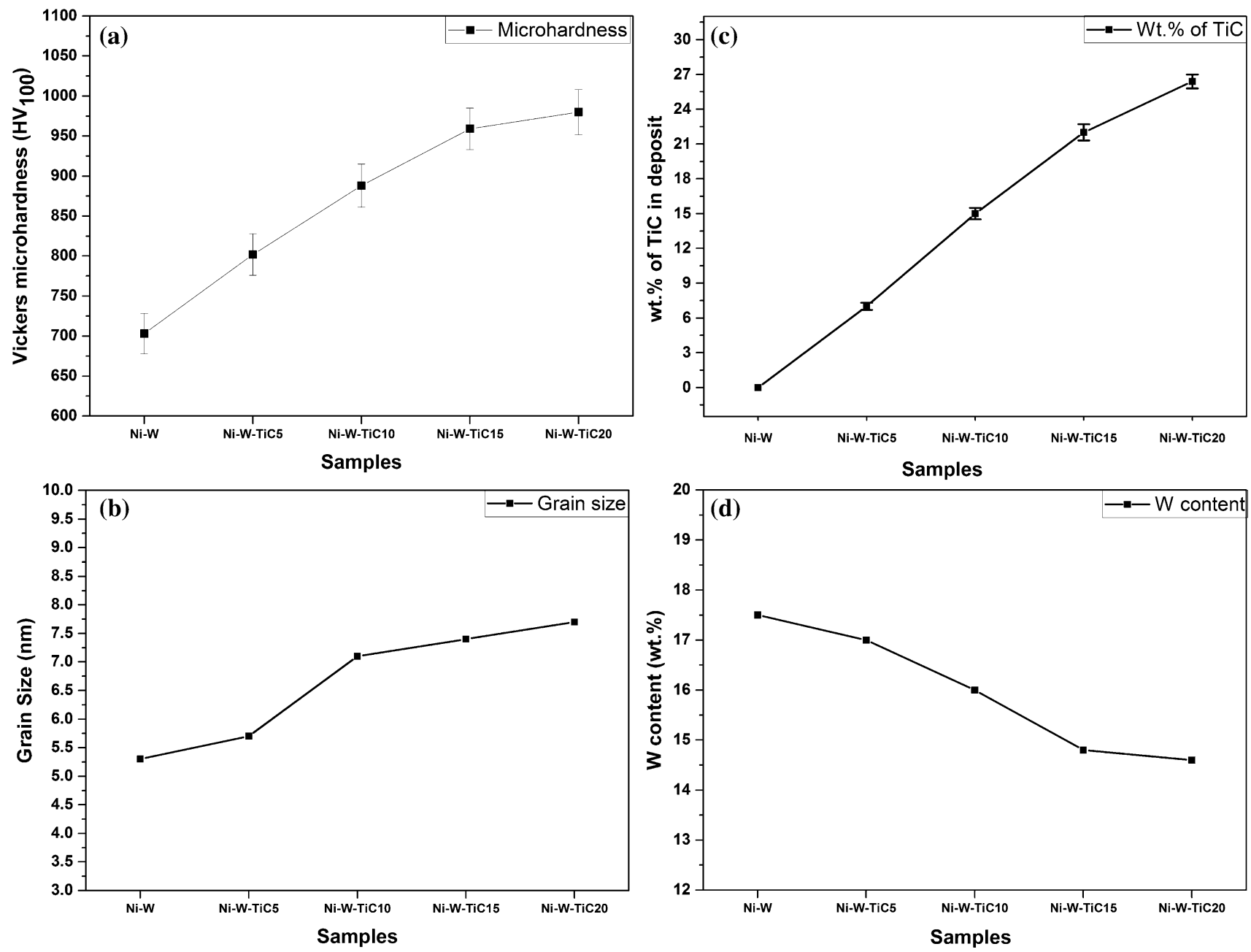

Fig. 5 Variation of a Vickers microhardness, $\mathbf{b}$ grain size, $\mathbf{c}$ weight percent of TiC codeposition, $\mathbf{d} \mathrm{W}$ content in Ni-W and Ni-W-TiC coatings

effect due to the incorporation of $\mathrm{TiC}$ particles. The codeposition weight percent of $\mathrm{TiC}$ particles into the deposit versus TiC particles loading into the plating bath is shown in Fig. 5c. The codeposition weight percent of $\mathrm{TiC}$ is increased by increasing the concentration of $\mathrm{TiC}$ particles in the plating bath. A gradual increase in codeposition weight percent was achieved until $15 \mathrm{~g} / \mathrm{L} \mathrm{TiC}$ particles in the plating bath. However, at $20 \mathrm{~g} / \mathrm{L}$ of $\mathrm{TiC}$ concentration, the codeposition rate is slightly reduced. This observation suggests the particle saturation limit in the plating bath or the existence of an optimal concentration of the dispersed particles for which the codeposition is effective. Dehgahi et al. [23] reported similar observation in their study where the maximum codeposition percentages of $\mathrm{Al}_{2} \mathrm{O}_{3}$ and $\mathrm{SiC}$ nanoparticles were achieved by dispersing $20 \mathrm{~g} / \mathrm{L}$ of nanoparticles in the plating bath. The optimal value of particles loading into the plating bath depends on several factors, including the nature and type of particles, particle size and shape, surface charge and their adsorption characteristics, surfactants, agitation type, electrode orientation, etc. Beyond the optimal value, the codeposition rate of particles decreases or sometimes may lead to the agglomerated clusters in the deposit. On the other hand, the alloying phase, $\mathrm{W}$, in the deposit, is also found to be slightly decreased over increasing content of codeposited TiC particles, as shown in Fig. 5d. Hou et al. [24] also observed that the $\mathrm{W}$ content was slightly decreased in Ni-W /diamond composite coatings by increasing diamond concentration in the plating bath. Hence, the decrease in $\mathrm{W}$ content might be one of the reasons for a slight increase in matrix grain size in the $\mathrm{Ni}-\mathrm{W}-\mathrm{TiC}$ composites as compared to bare $\mathrm{Ni}-\mathrm{W}$ alloy coating. However, the increment of $\mathrm{TiC}$ particles in the $\mathrm{Ni}-\mathrm{W}-\mathrm{TiC}$ coating is relatively higher than the decrease in $\mathrm{W}$ phase or increase in grain size. In other words, only a slight change in grain size and $\mathrm{W}$ content in the deposit occurred due to the effect of TiC incorporation in the matrix. 


\subsection{Tribological Properties}

Tribological properties of Ni-W and Ni-W-TiC composite coatings were evaluated by performing wear and coefficient of friction (COF) tests.

\subsubsection{Effect of TiC Particles on Friction and Wear Behaviors of the Coatings}

Figure 6 shows the variation of the coefficient of friction of $\mathrm{Ni}-\mathrm{W}$ and $\mathrm{Ni}-\mathrm{W}-\mathrm{TiC}$ composite coatings under $5 \mathrm{~N}$ load in the dry condition. Initially, the COF of all samples started with a lower value (Fig. 6; region I). After a minute of sliding time, $\mathrm{Ni}-\mathrm{W}$ coating possessed an almost constant value of the COF, so-called steady-state COF, till the end of the test. For Ni-W-TiC composite coatings, although it started with lower value, COF possessed the highest value until 3 min (Fig. 6; region II). Hence, it took around 3 min of sliding time to attain such steady-state COF (Fig. 6; region III). The reason behind this relatively long time to attain the steady-state COF is due to the presence of submicronsized $\mathrm{TiC}$ particles held tightly within the $\mathrm{Ni}-\mathrm{W}$ matrix. The counter ball continues to experience the dragging force until these particles plow out or overcome such irregularities in the partner surface. As soon as the contact surfaces have worn out to fit the irregularities, a steady-state value of the friction force is maintained. Compared to $\mathrm{Ni}-\mathrm{W}$ coating, $\mathrm{Ni}-\mathrm{W}-\mathrm{TiC}$ composite coatings have shown a lower value of the steady-state COF. It is interesting to note that as the amount of codeposited $\mathrm{TiC}$ particles increased, the coefficient of friction was decreased. Codeposition of ceramic particles into the metal matrix not only modulates the matrix grains but also reduces the friction force during the sliding

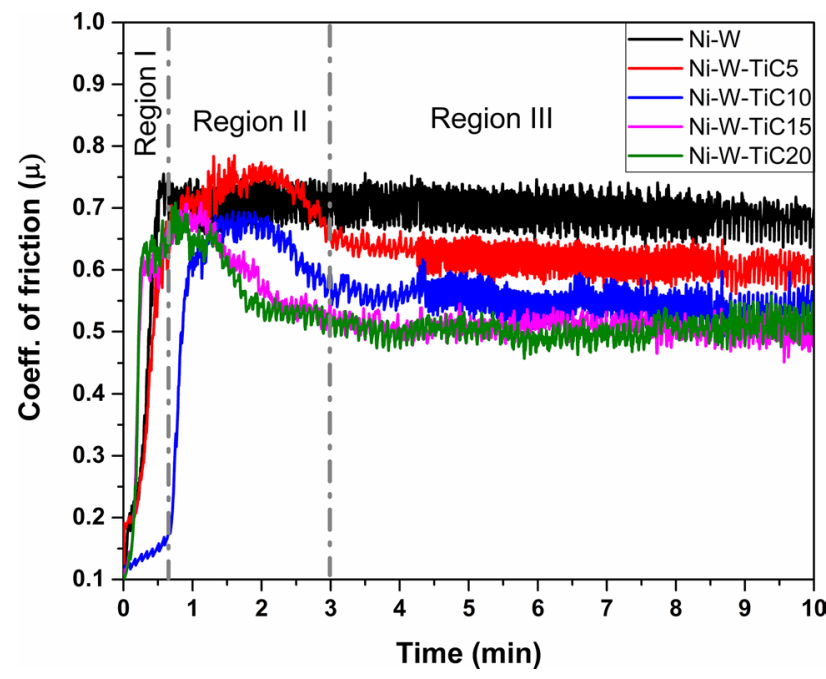

Fig. 6 Coefficients of friction of $\mathrm{Ni}-\mathrm{W}$ and $\mathrm{Ni}-\mathrm{W}-\mathrm{TiC}$ coatings obtained during the wear test contact. The effect is more pronounced when the content of ceramic particles is increased and homogeneously distributed. In addition, the microhardness of the coating was found to increase by increasing the content of $\mathrm{TiC}$ in the deposit (Fig. 5a). The coefficient of friction decreases linearly with the hardness [25]. Hence, decrease in coefficient of friction was observed by increasing TiC particles in the deposit. Our observation is well aligned with the published literature in nickel-based composite coatings [24, 26]. However, there is no significant difference in COF between $\mathrm{Ni}-\mathrm{W}-\mathrm{TiC} 15$ and $\mathrm{Ni}-\mathrm{W}-\mathrm{TiC} 20$ samples, and the trend shows almost similarity throughout the entire sliding time. It can be correlated with the tungsten content in the deposit, Vickers microhardness, and the codeposition percentage of TiC particles. Both the samples possessed similar values of microhardness. Also, there is no significant difference in $\mathrm{W}$ contents in Ni-W-TiC15 ( $14.8 \mathrm{wt} \%)$, and Ni-W-TiC20 $(\sim 14.6 \mathrm{wt} \%)$. However, only a slight increase in codeposition weight percent of $\mathrm{TiC}$ was observed in the $\mathrm{Ni}-\mathrm{W}-\mathrm{TiC} 20$ compared to the Ni-W-TiC15 sample. Hence, due to the optimal concentration of ceramics dispersion in the plating bath and their effective codeposition into the deposit, no significant difference in the coefficient of friction was observed between $\mathrm{Ni}-\mathrm{W}-\mathrm{TiC} 15$ and $\mathrm{Ni}-\mathrm{W}-\mathrm{TiC} 20$ samples.

SEM observation was performed to investigate the wornout surface of the samples after the tribology test. Figure 7 shows the SEM images of the worn surfaces of Ni-W and $\mathrm{Ni}-\mathrm{W}-\mathrm{TiC}$ composite coatings and the representative EDS spectrum of the worn track of Ni-W-TiC20 sample (Fig. 7e). All the samples possess abrasive wear and no characteristic features observed for the adhesive nature of wear. A plow out of materials and the transferred film from the counter body are promising evidence for the abrasive nature of the wear mechanism. As the content of TiC increased in the sample, the amount of transferred film from the counter steel ball was also increased (see Fig. 7e), whereas the plowed-out materials from the sample surface decreased. It might be due to the increase in hardness and the content of TiC particles. TiC particles are well known for their high hardness and excellent thermal stability. Hence, TiC particles might have played a crucial role in resisting the abrasive wear during the dry sliding process [27]. In addition, microhardness values of $\mathrm{Ni}-\mathrm{W}$ and $\mathrm{Ni}-\mathrm{W}-\mathrm{TiC} 5$ samples are lower than the sliding counter steel ball $(\sim 830 \mathrm{HV})$, whereas the $\mathrm{Ni}-\mathrm{W}-\mathrm{TiC} 10, \mathrm{Ni}-\mathrm{W}-\mathrm{TiC} 15$, and $\mathrm{Ni}-\mathrm{W}-\mathrm{TiC} 20$ samples possess higher microhardness compared to the sliding steel ball. Hence, for the samples having higher microhardness than the counter ball, transferred films from the counter ball are observed. The EDS spectrum of the worn surface of the $\mathrm{Ni}-\mathrm{W}-\mathrm{TiC} 20$ sample revealed a significant amount of iron that has been transferred from the steel ball.

Wear rates of the Ni-W and $\mathrm{Ni}-\mathrm{W}-\mathrm{TiC}$ coatings were analyzed by measuring the material loss with reference to 

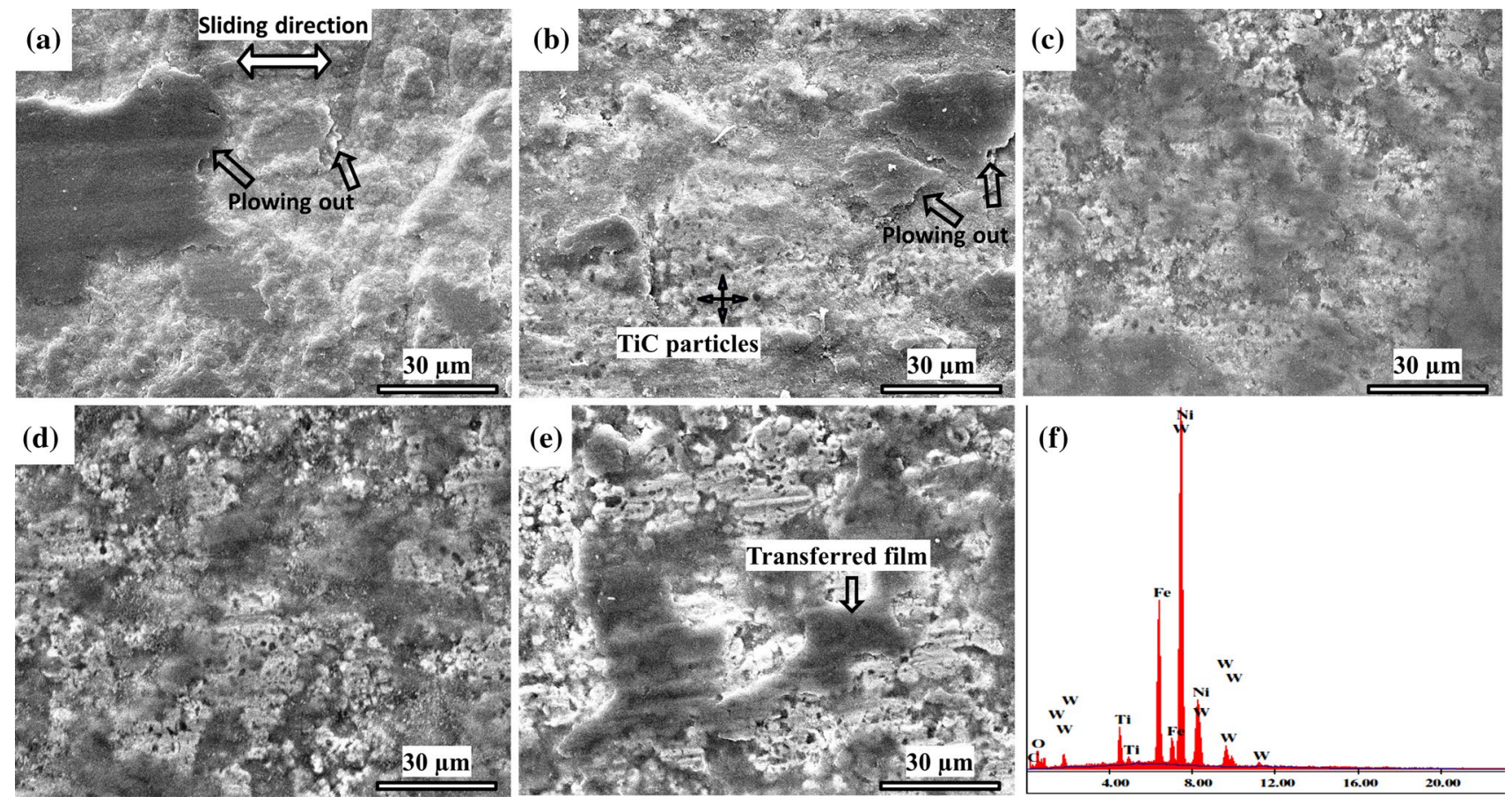

Fig. 7 SEM images of the worn-out surfaces of a Ni-W, $\mathbf{b} \mathrm{Ni}-\mathrm{W}-\mathrm{TiC}$, $\mathbf{c} \mathrm{Ni}-\mathrm{W}-\mathrm{TiC} 10, \mathbf{d} \mathrm{Ni}-\mathrm{W}-\mathrm{TiC} 15$, e Ni-W-TiC20 coatings; $\mathbf{f}$ EDS spectrum of the worn surface of $\mathrm{Ni}-\mathrm{W}-\mathrm{TiC} 20$ sample

the wear width and depth characteristics. Figures 8 and 9 show the wear track width/depth profiles of Ni-W and $\mathrm{Ni}-\mathrm{W}-\mathrm{TiC}$ composite coatings and wear rates, respectively. $\mathrm{Ni}-\mathrm{W}$ coating has the widest wear track among all samples. As the TiC content was increased in the deposit, the width/ depth profile of the wear track was decreased. The result indicates an improvement of the wear-resistant behavior of the coating due to the presence of $\mathrm{TiC}$ particles in the deposit. Similarly, the wear rate of Ni-W-TiC composite coating was decreased with increasing content of TiC particles into the deposit, as revealed from Fig. 9. Ni-W only coating, on the other hand, has shown the highest wear rate among all the samples. As described above, TiC particles are held tightly within the Ni-W matrix, thereby improving the micromechanical properties of the coating in the composite system. Therefore, the composite coating exhibited an increased sliding wear resistance as compared to the $\mathrm{Ni}-\mathrm{W}$ coating.

\subsubsection{Effect of Applied Load and Sliding Speed on COF of the Coating}

The Ni-W-TiC20 sample was investigated with a series of $3 \mathrm{~N}, 5 \mathrm{~N}, 7.5 \mathrm{~N}$, and $10 \mathrm{~N}$ loads to study the effect of applied load on the tribological performance of the coatings. In general, increase in applied load decreases the COF during the tribology test in metal-metal sliding contacts. Figure 10a shows the plot of COF versus different loads. The

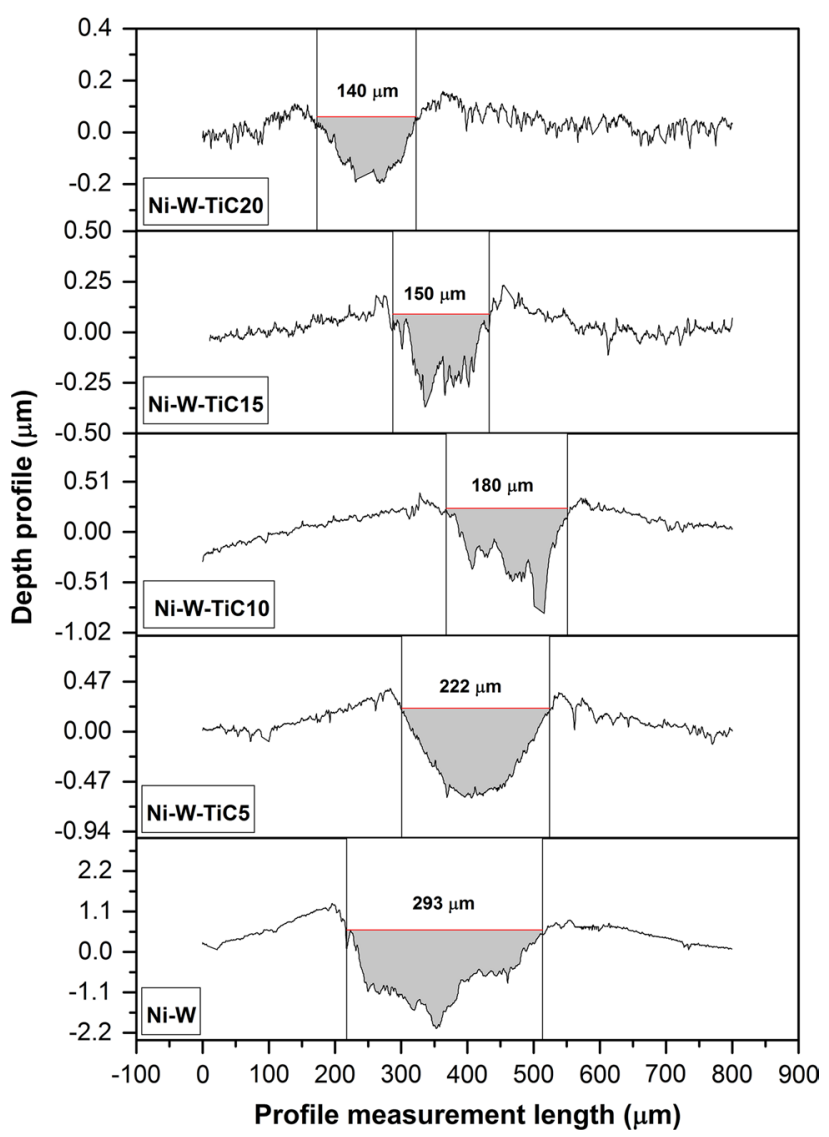

Fig. 8 Wear track width/depth profiles of Ni-W and Ni-W-TiC coatings 


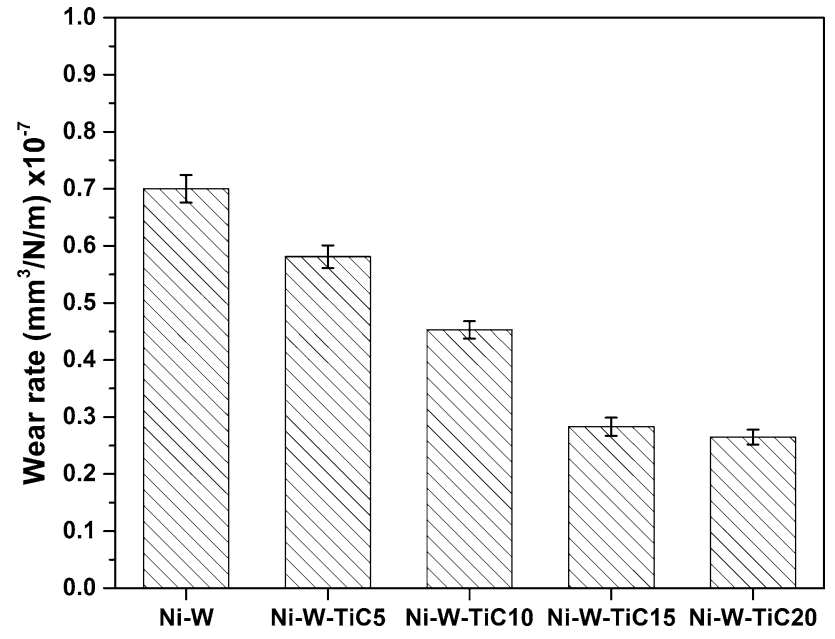

Fig. 9 Wear rates of $\mathrm{Ni}-\mathrm{W}$ and $\mathrm{Ni}-\mathrm{W}-\mathrm{TiC}$ coatings
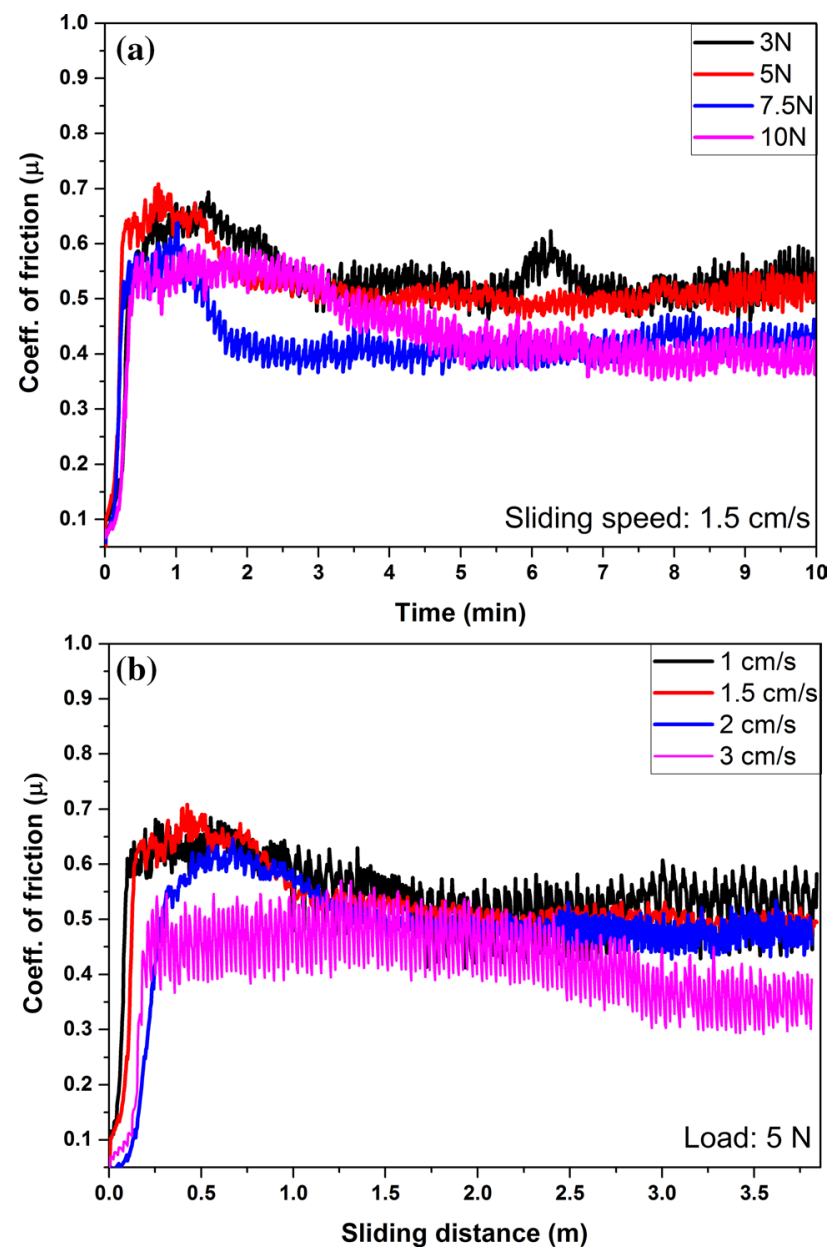

Fig. 10 Variation of the coefficient of friction of Ni-W-TiC20 sample under a load variation, b sliding speed variation
COF gradually decreased by increasing loads until $7.5 \mathrm{~N}$. The formation of oxidative film and third-body lubricity due to smashed debris might be the possible reasons to decrease COF. However, at $10 \mathrm{~N}$ load, the nature of COF is slightly different. It took around $5 \mathrm{~min}$ of initial sliding time to attain the steady-state COF. Furthermore, the average value of $\mathrm{COF}$ at the initial $5 \mathrm{~min}$ is higher than the one with a $7.5 \mathrm{~N}$ load. The marginally higher average value of the COF at the initial 5 min of sliding time in $10 \mathrm{~N}$ load can be ascribed to the increased initial abrasion rate and the roughening of the mating surfaces. As a result, the increase in friction force caused to increase the coefficient of friction at initial 5-min sliding period. After this period, roughness and other parameters might have attained to an equilibrium state.

Figure 10b shows the variation of $\mathrm{COF}$ of $\mathrm{Ni}-\mathrm{W}-\mathrm{TiC} 20$ composite coating obtained at different sliding speeds under the fixed $5 \mathrm{~N}$ load. It has been observed that the values of COF decreased by increasing sliding speed. The decrease in COF by increasing sliding speed may be explained based on the duration of contact, momentum transfer in the normal direction, and the real area of contact. In other words, the friction force is a function of velocity and time of contact. The friction force is also proportional to the time of contact. Increasing the sliding speed increases the momentum transfer in the normal direction producing an upward force on the top surface. It results in an increased separation between two mating surfaces and thus decrease in the real area of contact [28]. Hence, decrease in real area of contact decreases the friction force.

\section{Conclusion}

$\mathrm{Ni}-\mathrm{W}-\mathrm{TiC}$ composite coatings were successfully prepared by the electrodeposition technique. Increased content of $\mathrm{TiC}$ in the $\mathrm{Ni}-\mathrm{W}-\mathrm{TiC}$ composite coating led to relatively higher surface roughness or coarser surface topography, enhancement of Vickers microhardness, and decrease in average coefficient of friction and wear rates. Nevertheless, crystallite grain size and $\mathrm{X}$-ray diffraction patterns of the $\mathrm{Ni}-\mathrm{W}$ matrix were not significantly altered by the incorporation of $\mathrm{TiC}$ particles into the coatings. Abrasive wear was found to be predominant wear mechanism in Ni-W and $\mathrm{Ni}-\mathrm{W}-\mathrm{TiC}$ composite coatings. Hence, from this study, electrodeposited $\mathrm{Ni}-\mathrm{W}-\mathrm{TiC}$ composite coatings containing $15-25 \mathrm{wt} \%$ of $\mathrm{TiC}$ are recommended as promising candidates to the wearresistant hard-coatings for tribological applications.

Acknowledgements This research was supported by the "International standardization of nickel-phosphorous ceramics electroless composite plating for industrial use" program through the "Korea Evaluation Institute of Industrial Technology" of Korea funded by the Ministry of Science, ICT and Future planning (Grant No. 10080067) 


\section{References}

[1] Z. Mahidashti, M. Aliofkhazraei, N. Lotfi, Trans. Indian Inst. Met. 71, 257 (2018)

[2] W. Jiang, L. Shen, M. Xu, Z. Wang, Z. Tian, J. Alloys Compd. 791, 847 (2019)

[3] I. Gurrappa, L. Binder, Sci. Technol. Adv. Mater. 9, 043001 (2008)

[4] G. Gyawali, K. Tripathi, B. Joshi, S.W. Lee, J. Alloys Compd. 721, 757 (2017)

[5] F. Su, C. Liu, P. Huang, Appl. Surf. Sci. 309, 200 (2014)

[6] N. Tsyntsaru, H. Cesiulis, M. Donten, J. Sort, E. Pellicer, E.J. Podlaha-Murphy, Surf. Eng. Appl. Electrochem. 48, 491 (2012)

[7] H.A. Kishawy, in: Mach. Technol. Compos. Mater. (Elsevier, 2012), p. 3-16.

[8] J.W. Kaczmar, K. Pietrzak, W. Włosiński, J. Mater. Process. Technol. 106, 58 (2000)

[9] R. Casati, M. Vedani, Metals (Basel) 4, 65 (2014)

[10] D. Miracle, Compos. Sci. Technol. 65, 2526 (2005)

[11] G. Gyawali, R. Adhikari, H.S. Kim, H.-B. Cho, S.W. Lee, ECS Electrochem Lett. 2, C7 (2013)

[12] A. Emamian, S.F. Corbin, A. Khajepour, Surf. Coat. Technol. 206, 4495 (2012)

[13] K.H. Hou, Y.C. Chen, Appl. Surf. Sci. 257, 6340 (2011)

[14] B. Li, W. Zhang, W. Zhang, Y. Huan, J. Alloys Compd. 702, 38 (2017)
[15] F. Akhtar, S.J. Guo, Mater. Charact. 59, 84 (2008)

[16] L. Benea, N. Ege Caron, O. Raquet, RCS Adv. 6, 59775 (2016)

[17] L. Benea, J.P. Celis, Materials (Basel). 9, 269 (2016)

[18] K. Zielińska, A. Stankiewicz, I. Szczygieł, J. Colloid Interface Sci. 377, 362 (2012)

[19] G. Gyawali, S.H. Cho, D.J. Woo, S.W. Lee, Trans. Inst. Met. Finish. 90, 274 (2012)

[20] Y. Zhu, Y. Chen, C. Zhu, X. Shen, Acta Metall. Sin. (Engl. Lett.) 23, 409 (2010).

[21] E. Bełtowska-Lehman, A. Góral, P. Indyka, Arch. Metall. Mater. 56, 924 (2011).

[22] K. Arunsunai Kumar, G. Paruthimal Kalaignan, V.S. Muralidharan, Ceram. Int. 39, 2827 (2013).

[23] S. Dehgahi, R. Amini, M. Alizadeh, J. Alloys Compd. 692, 622 (2017)

[24] K.H. Hou, H.T. Wang, H.H. Sheu, M.D. Ger, Appl. Surf. Sci. 308, $372(2014)$

[25] A.J.W. Moore, W.J.M. Tegart, F.P. Bowden, Proc. R. Soc. Lond. Ser. A. Math. Phys. Sci. 212, 452 (1952)

[26] X.J. Sun, J.G. Li, Tribol. Lett. 28, 223 (2007)

[27] Y.J. Dong, H.M. Wang, Surf. Coat. Technol. 204, 731 (2009)

[28] M.A. Chowdhury, M.K. Khalil, D.M. Nuruzzaman, M.L. Rahaman, Int. J. Mech. Mech. Eng. 11, 53 (2011) 